\title{
Intraparenchymal Atypical Meningioma in Basal Ganglia Region in a Child : Case Report and Literature Review
}

\author{
Xiaowei Liu, M.M., Yuekang Zhang, M.D., Si Zhang, M.D., Chuanyuan Tao, M.D., Yan Ju, M.D. \\ Department of Neurosurgery, West China Hospital, Sichuan University, Chengdu City, Sichuan Province, China
}

Intraparenchymal meningiomas without dural attachment are extremely rare, especially when they occur in basal ganglia region in child. An 8-year-old boy was admitted at our hospital, complaining of recurrent headache and vomiting for 3 months. Neurological examination showed impaired vision and mild paresis of the left extremities. Magnetic resonance imaging demonstrated a lesion located in the right basal ganglia region extending to superasellar cistern with solid, multiple cystic and necrotic components. Computed tomography revealed calcification within the mass. Due to the anterior cerebral artery involvement, a subtotal resection was achieved and postoperative radiotherapy was recommended. Histopathological examination indicated that the lesion was an atypical meningioma. The postoperative rehabilitation was uneventful. Mildly impaired vision and motor weakness of left extremities improved significantly and the patient returned to normal life after surgery. To our knowledge, intraparenchymal atypical meningioma in basal ganglia extending to superasellar cistern was never reported. The significance in differential diagnosis of lesions in basal ganglia should be emphasized.

Key Words : Intraparenchymal meningioma · Basal ganglia · Atypical meningioma.

\section{INTRODUCTION}

Meningiomas are the most common benign tumors among central nervous system (CNS) neoplasms ${ }^{1)}$. However, meningiomas are rare in childhood and adolescence, representing only $0.4-4.6 \%$ of all CNS tumors ${ }^{5}$. Those located in intraparenchymaare much more rare without dural attachment ${ }^{3)}$.

Intraparenchymal meningiomas, also considered as the same type of subcortical meningiomas, are defined as meningiomas located in brain parenchyma without dural attachment, occasionallyreaching the brain surface $e^{2,4,6)}$. To our best knowledge, there are only 18 intraparenchymal meningiomas in children reported in the literature, with most of them in the cerebral lobes $^{2,6-20)}$.

Here we report the first case of primary intraparenchymal meningioma in the deep basal ganglia region in children and review the pertinent literature to discuss the clinical presentation and management, radiological features, and possible pathogenesis. The significance in differential diagnosis of lesions in basal ganglia is also emphasized.

\section{CASE REPORT}

An 8-year-old boy presented at our hospital complaining of

- Received : June 10, 2015 •Revised : October 24, 2015 •Accepted : October 25, 2015

- Address for reprints : Yan Ju, M.D.

Department of Neurosurgery, West China Hospital, Sichuan University, Guoxue lane N0.37, Chengdu, Sichuan 610041, China

Tel : +86-028-18980601975, Fax : +86-028-85422488, E-mail : 1229013105@qq.com

This is an Open Access article distributed under the terms of the Creative Commons Attribution Non-Commercial License (http://creativecommons.org/licenses/by-nc/4.0) which permits unrestricted non-commercial use, distribution, and reproduction in any medium, provided the original work is properly cited. 
recurrent headache and vomiting for 3 months. The patient saw a doctor in a clinic before admission to our hospital and took some medicine for cold. The symptoms got relief temporarily but became severe 1 week ago.

Neurological examination showed impaired vision and mild paresis (IV-grade of muscle strength) of the left extremities. CT (Fig. 1A, B) revealed an iso- to hyperdense lesion in the right basal ganglion extending to superasellar cistern, $4.0 \times$ $4.4 \mathrm{~cm}$ in sizewith peripheral calcification. No hyperostosis of sellaturcica was noticed (Fig. 1C). Magnetic resonance imaging (MRI) demonstrated most of the mass lesion was iso-intense on T1-weighted, T2-weighted and fluid-attenuated inversion recovery images with inhomogeneous enhancement (Fig. 2A-E). No duraltail sign was noted. Diffusion tensor image revealed the right pyramidal tract was partially disrupted.

Under the guide of navigation, a transcortical (through the right middle frontal gyrus) approach was adopted to explore the lesion. There was no dural attachment, but the tumor was tightly adhered with the anterior cerebral artery (ACA). Small vessels supplied the anterior aspect of the tumor, subtotal resection (STR) was achieved.

Histopathological examination revealed features of atypical meningioma with Ki-67 labeling index been approximately 10\% (Fig. 3A-C). Immunohistochemistry showed the tumorpositive for epithelial membrane antigen and negative for glial fibrillary acidic protein and S-100 protein (Fig. 3D-F).

The patient suffered transient exacerbation of impaired vision and weakness of contralateral limbs after operation, which resolved significantly after 3 months follow-up. Postop- erative MRI revealed that most of the tumor had been resected and the residual part has been detached from dorsumsellae (Fig. 2F).

\section{DISCUSSION}

\section{Clinical presentation}

Primary intraparenchymal meningiomas are rare, but more frequent in children and adolescents than in adults ${ }^{7)}$. To date, only 19 patients including ours, have been reported in the English-language literatures, which are summarized in Table $1^{2,6-22)}$. The age ranged from 0 to 18 years. Gender distribution showed a male dominance $(\mathrm{n}=14,73.7 \%)$ in children and adolescents. The most common location was frontal lobe $(n=8$, $42.1 \%)$, followed by temporal lobe $(n=5,26.3 \%)$, parietal lobe $(n=2,10.5 \%)$, frontoparietal lobe $(n=1,5.3 \%)$, parietooccipital lobe $(n=1,5.3 \%)$, brainstem $(n=1,5.3 \%)$ and basal ganglia extending to superasellar cistern (our case, $n=1,5.3 \%$ ). Presenting symptoms depend on tumor location and intracranial pressure, and seizure $(n=13,68.4 \%)$ was most frequent.

\section{Management, features of histopathology and prognosis}

Gross total resection (GTR) were achieved in 15 of 19 cases (78.9\%). There was 70\% remnant in one patient, because of the lesion in brainstem ${ }^{11)}$. Another patient got subtotal resection, but the reason was not stated ${ }^{18)}$. The study by Kotecha et
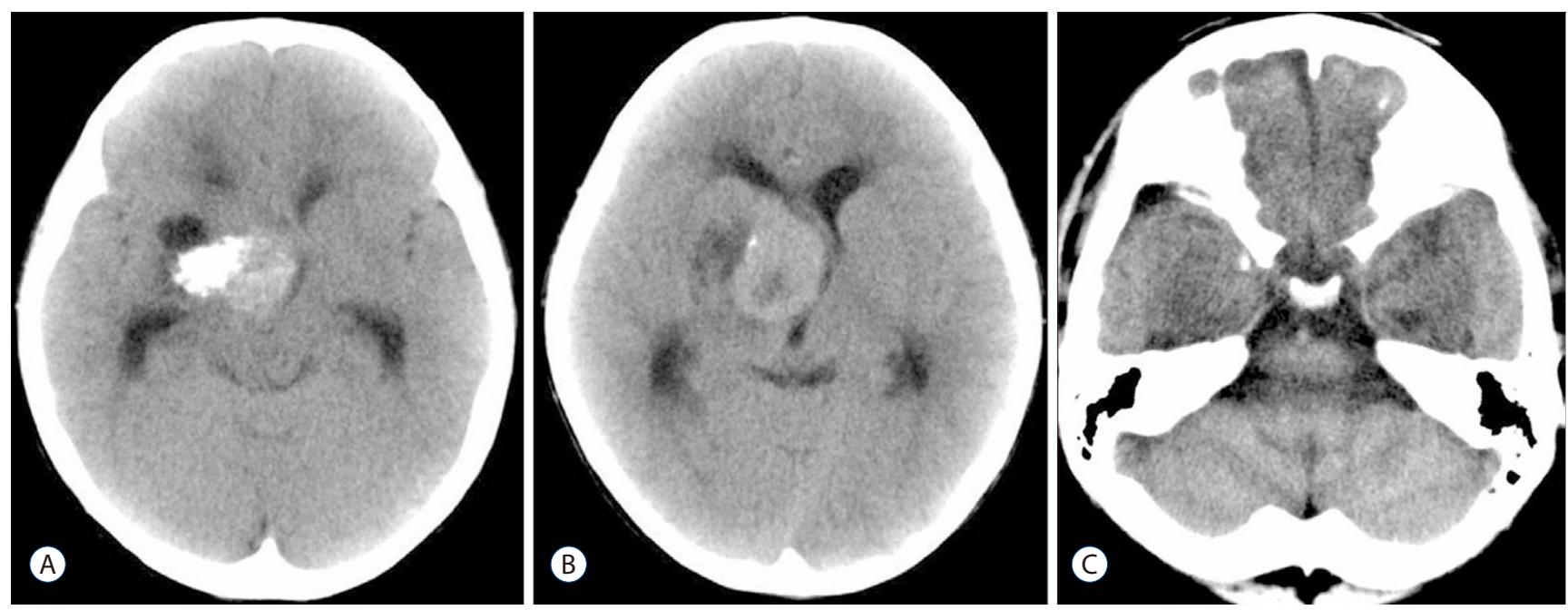

Fig. 1. CT revealing calcification, necrosis, cystic formation of the mass lesion (A and B). No hyperostosis or bone absorbtion was observed (C). 

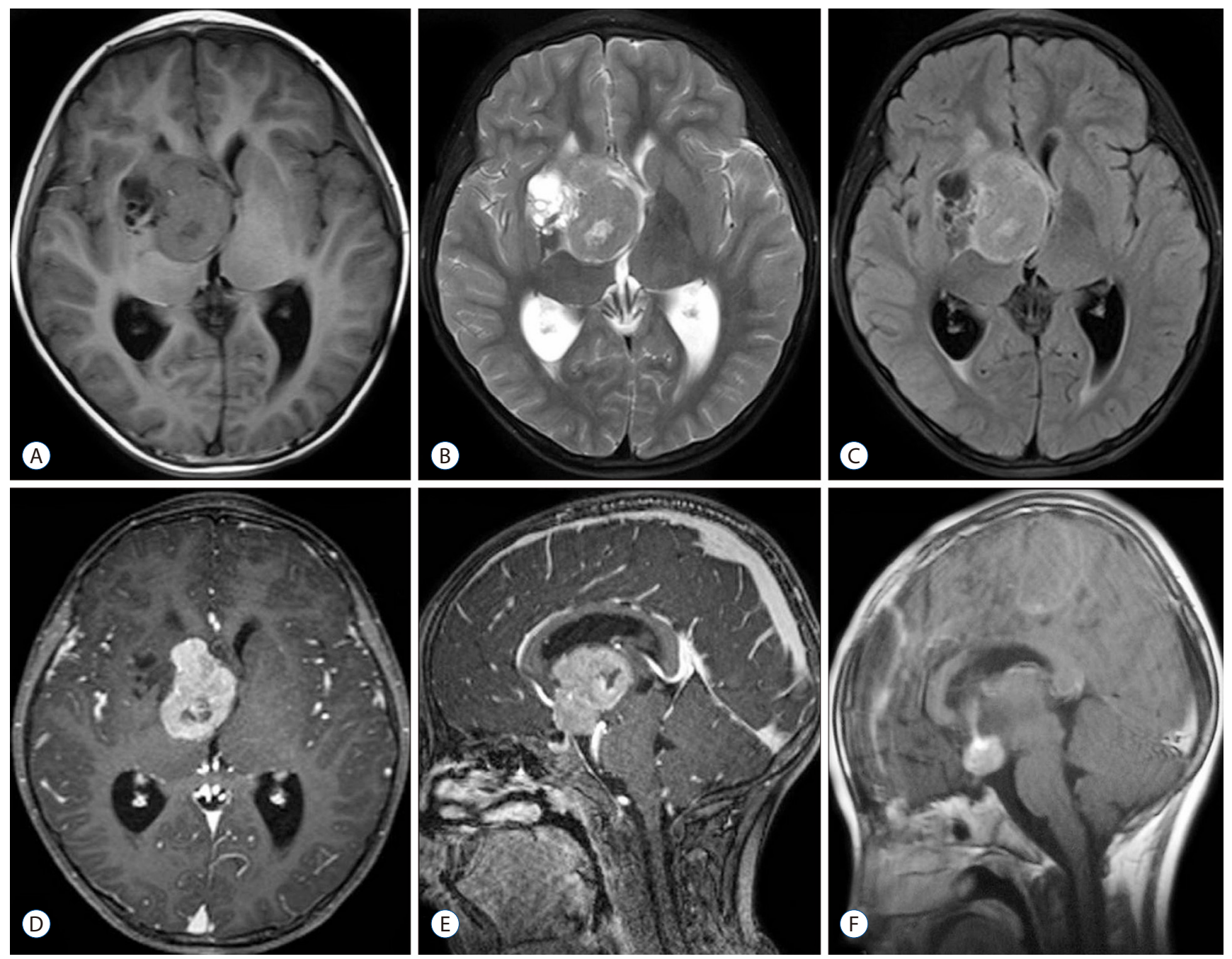

Fig. 2. MRI showing a mass lesion in the right basal ganglia consisted of solid and cystic parts. The solid part manifesting isointense signal on T1weighted (A), T2-weighted (B), and FLAIR (C) with heterogeneous enhancement ( $D$ and E); the cystic part showing hypointense signal on both T1weighted (A) and FLAIR (C) and hyperintensity on T2-weighted images (B) without enhancement of the wall (D and E). Although the lower margin of the tumor touched the dorsum sellae dura, 'dura tail' sign was not noted (E). Postoperative MRI revealing that most of the tumor has been resected and the residual part detached from the dorsum sellae (F). Subdural fluid accumulation in the surgical region was also detected (F). FLAIR : fluid attenuation inversion recovery, $\mathrm{MRI}$ : magetic resonance imaging.

al. ${ }^{14,16)}$ showed that extent of initial surgical resection was the strongest independent prognostic factor for pediatric meningiomas and upfront radiotherapy achieved no benefit. Hence, GTR was thetreatment of choice. In our case, STR was performed because of the rich blood supply, tight adhesion with ACA and lower tolerance of blood loss in children.

Zhang et al. ${ }^{34)}$ and Starshak ${ }^{30)}$ treated patients with malignant meningiomas with postoperative radiotherapy. However, postoperative radiotherapy was controversial. Some people thought meningioma could be induced by radiation ${ }^{23}$. Others suggested that adjuvant radiotherapy might delay recurrence of malignant meningiomas or progression of residual meningiomas $^{24)}$. Our case received postoperative radiotherapy because of the atypical meningioma and residual tumor growing.

Intraparenchymalmeningiomas were generally benignin children ( $\mathrm{n}=11,64.7 \%)$. Intraparenchymal atypical meningioma was first showed in zhang's study ${ }^{2}$. In our patient, the lesion also proved to be atypical meningioma (World Health Organization-II).

The prognosis is worse in pediatric than in adult population, depending on the degree of excision, pathologic grade, 

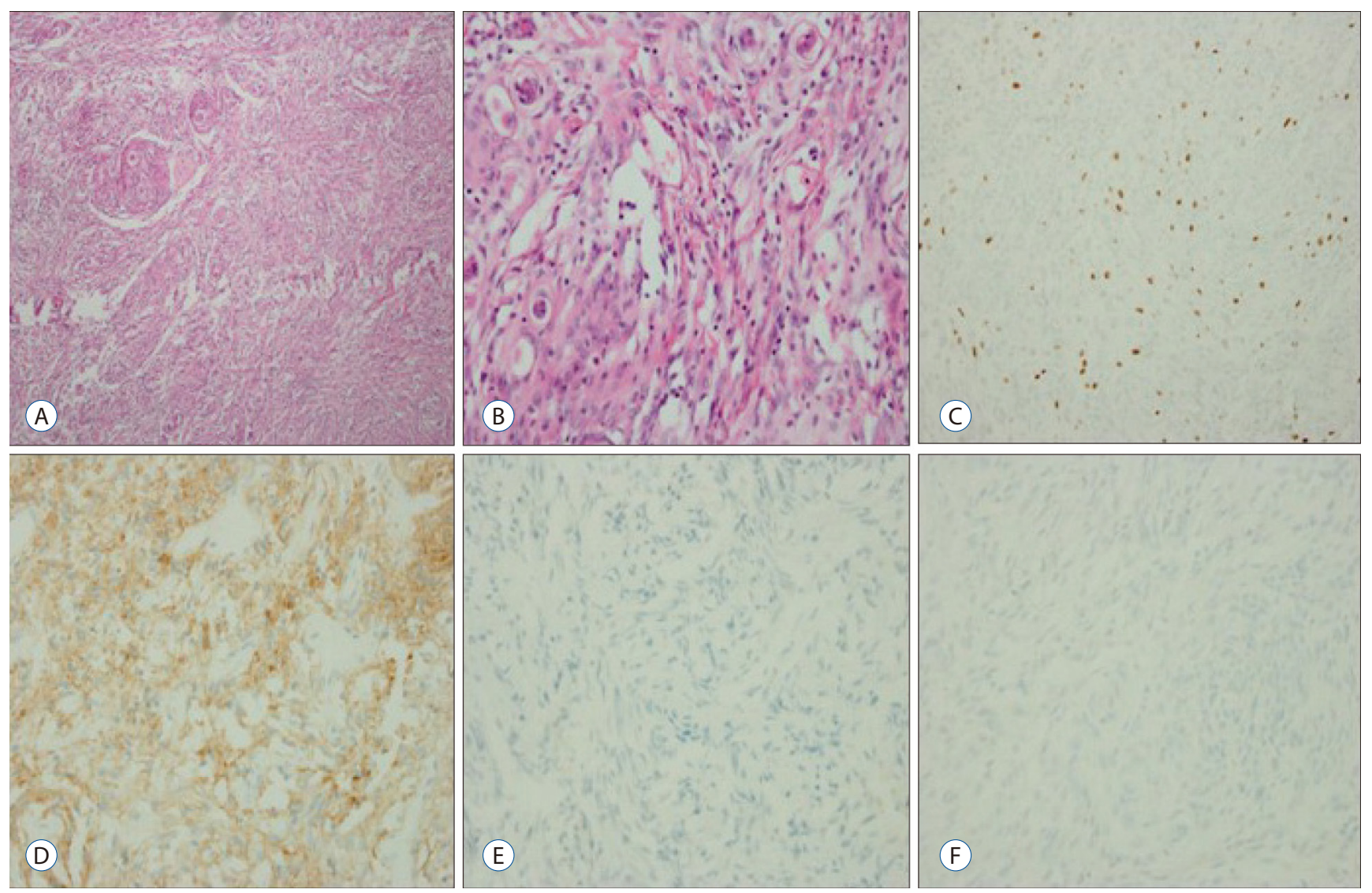

Fig. 3. Hematoxylin-eosin staining exhibiting sheetlike growth, foci of spontaneous, increased cellularity, small cells with a high nucleus-to-cytoplasm ratio and prominent nucleoli (A : original magnification, $\times 100$; B : original magnification, $\times 400$ ). Immunohistochemical staining showing positive for epitheliod membrane antigen ( $D$ : original magnification, $\times 400$ ), but negative for glial fibrillary acidic protein ( $E$ : original magnification, $\times 400)$ and $S-100$ protein ( $\mathrm{F}$ : original magnification, $\times 400)$. Ki-67 labeling index being approximately $10 \%$ (C : original magnification, $\times 400)$.

tumor location and association with neurofibromatosis ${ }^{14,16,25)}$. The 10-year recurrence rate for GTR and STR is 33\% and $82 \%$, respectively ${ }^{11}$. Hence, Kotecha et al. ${ }^{14,16)}$ suggested the follow-up should be once every three months for at least 10 years and all life time for those with GTR or STR.

\section{Features of radiology}

The radiological features of pediatric primary intraparenchymal meningiomasinclude cystic component, calcification, large volumes and peritumoral edema. Compared with other meningiomas, the key difference of intraparenchymal meningiomas is the absence of dural attachment ${ }^{10,27)}$.

\section{Differential diagnosis}

The main radiological differential diagnosis for basal ganglia meningiomasincludes gliomas, lymphomas and germinomas, but sometimes it is quite difficult by imaging findings alone. Generally, low grade gliomas are usually iso- to hypodense on un-enhanced CT scans, whereas germinomas and lymphomas are of high density ${ }^{5,12,21,24,28)}$. With progression and emergence of apredominantly solid component, it is more difficult to distinguish non-typical meningiomasfrom gliomas, germinomas or lymphomas, all of which are iso-dense to hyper-dense on un-enhanced CT scans and relatively isointense on all MR pulse sequences ${ }^{5,12,21,24,28)}$. Cystic changes, intratumoral hemorrhage and heterogeneous enhancement are more frequently seen in germinomas and gliomas ${ }^{24}$. However, with the similar large size, peritumoral edema and mass effect are usually slighter in meningiomas than in gliomas. Hence, clinical manifestation and other supplementary examinations should be considered in such circumstances. For instance, it's helpful to identifygerminomas with tumor markers in serum and CSF or lymphoma with elevated lymphocytes percentage in peripheral blood and $\operatorname{CSF}^{5,12,21,24,28)}$. Careful evaluation of 


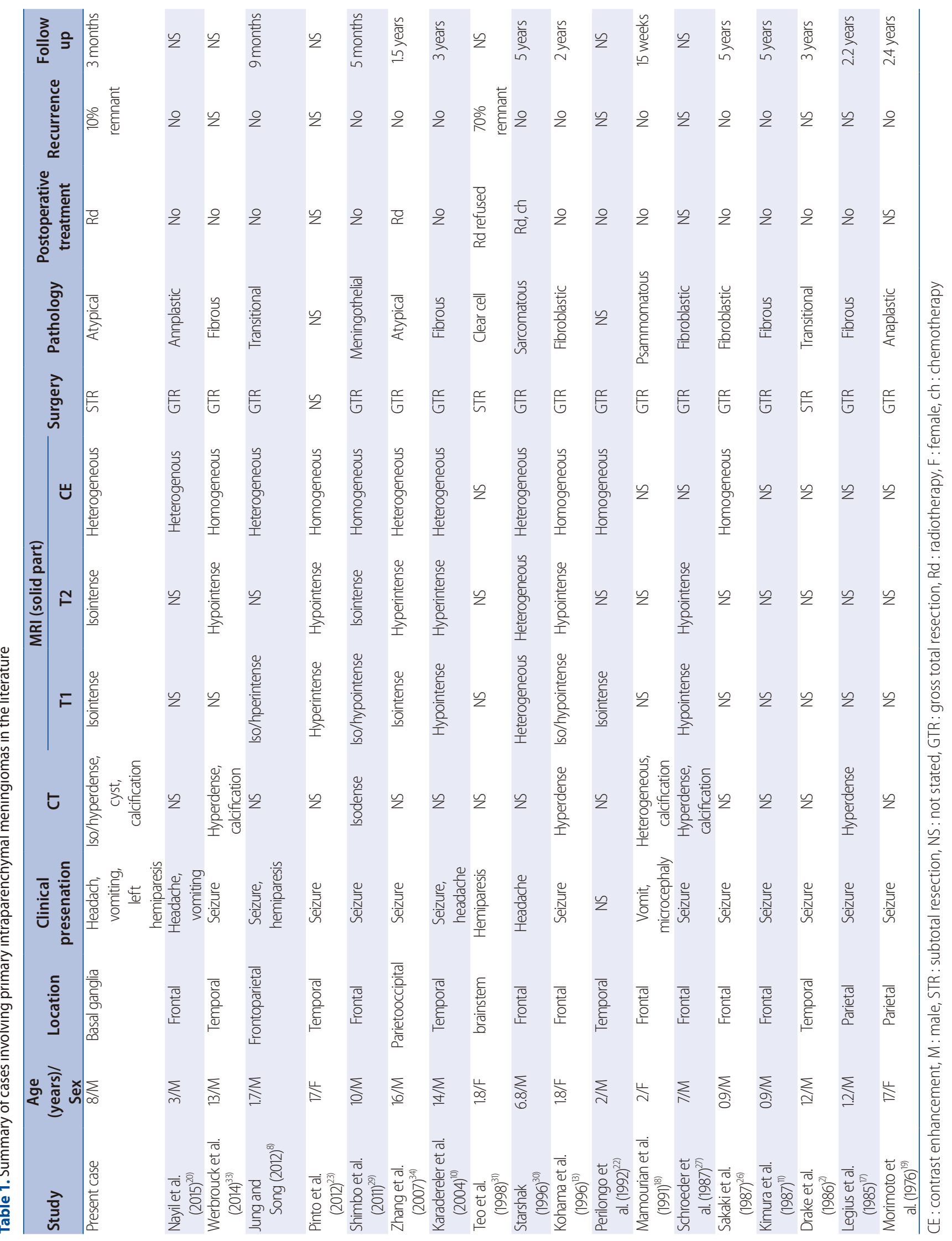


radiologic features should be emphasized, which would assist in selection of the preferred treatment for patients.

\section{Pathogenesis of primary intraparenchymal me- ningiomas}

The pathogenesis of primary intraparenchymal meningiomas is unclear. Some theories are proposed to explain the possible mechanism : 1) intraparenchymal meningiomas arise from arachnoid cells of the piamater, which enter the brain along with perforating blood vessels ${ }^{6,18,32,35)}$; 2) the meningiomas, which arise from the piamater of brain sulcus, adheres and compresses the brain parenchyma, and grows into the intraparenchymal lesion, so the mass is seen to be completely buried in the parenchyma ${ }^{29)}$; 3) some authors presume that the arachnoid cells rest during the migration progress ${ }^{6}$; 4) intraparenchymal meningiomas are believed to arise from ectopic meningothelial cells within the stroma of the pia mater ${ }^{6,18,32,35)}$; and 5) the occurrence may be due to cellular dedifferentiation within the cerebral parenchyma, or they may arise from the sheath cells of cranial nerves, which is proposed as the similar mechanism for the equally uncommon cutaneous meningioma and intradiploic meningioma ${ }^{3)}$. The first two theories are the most probable mechanisms to explain the origin in our case, based on the close relationship with the perforating arteries of ACA and middle cerebral artery and recurrent artery of Heubner, the imaging features and intraoperative findings.

\section{CONCLUSION}

For lesions of basal ganglion extending to the superasellar region, lack of dural attachment is the key neuroimaging feature for differentiating intraparenchymal meningiomas from tuberculum sellae, clinoid, sphenoid wing and cavernous sinus meningiomas. Intraparenchymal meningiomas should be considered when gliomas, lymphomas, germinomas and other common lesions are excluded. The intraparenchymal atypical meningioma of basal ganglion in child is firstly reported, which should be emphasized in differential diagnosis to assist in selection of the preferred treatment for patient or avoiding a delay in management.

\section{PATIENT CONSENT}

The patient provided written informed consent for the publication and the use of their images.

\section{References}

1. Amirjamshidi A, Mehrazin $M$, Abbassioun $K$ : Meningiomas of the central nervous system occurring below the age of 17: report of 24 cases not associated with neurofibromatosis and review of literature. Childs Nerv Syst 16 : 406-416, 2000

2. Drake JM, Hendrick EB, Becker LE, Chuang SH, Hoffman HJ, Humphreys RP : Intracranial meningiomas in children. Pediatr Neurosci 12 : 134 139, 1985-1986

3. Iannelli A, Pieracci N, Bianchi MC, Becherini F, Castagna M : Primary intra-diploic meningioma in a child. Childs Nerv Syst 24 : 7-11, 2008

4. Im SH, Wang KC, Kim SK, Oh CW, Kim DG, Hong SK, et al. : Childhood meningioma : unusual location, atypical radiological findings, and favorable treatment outcome. Childs Nerv Syst 17 : 656-662, 2001

5. Higano S, Takahashi S, Ishii K, Matsumoto K, Ikeda H, Sakamoto K : Germinoma originating in the basal ganglia and thalamus: MR and CT evaluation. AJNR Am J Neuroradiol 15 : 1435-1441, 1994

6. Jadik S, Stan AC, Dietrich U, Pietilä TA, Elsharkawy AE : Intraparenchymal meningioma mimicking cavernous malformation: a case report and review of the literature. J Med Case Rep 8 : 467, 2014

7. Jiang $X B$, Ke C, Han ZA, Lin SH, Mou YG, Luo RZ, et al. : Intraparenchymal papillary meningioma of brainstem: case report and literature review. World J Surg Oncol $10:$ 10, 2012

8. Jung YS, Song YJ : Meningioma in a 20-month-old boy. J Korean Neurosurg Soc $51: 219-221,2012$

9. Kamoshima Y, Terasaka S, Kobayashi H, Kaneko S, Kubota K, Tanaka $S$, et al. : Radiation induced intraparenchymal meningioma occurring 6 years after CNS germinoma: case report. Clin Neurol Neurosurg 114 1077-1080, 2012

10. Karadereler $S$, Aker $F$, Berkman $Z$ : Intraparenchymal meningioma in a child. Case report and review of the literature. J Neurosurg 101 (1 Suppl) : 112-115, 2004

11. Kimura H, Nakagawa K, Sakaki S, Matsuoka K : Intracranial meningioma of an infant : a case report. No Shinkei Geka $15: 663-668,1987$

12. Kobayashi T, Yoshida J, Kida Y : Bilateral germ cell tumors involving the basal ganglia and thalamus. Neurosurgery 24 : 579-583, 1989

13. Kohama I, Sohma T, Nunomura K, Igarashi K, Ishikawa A : Intraparenchymal meningioma in an infant--case report. Neurol Med Chir (Tokyo) 36 : 598-601, 1996

14. Kotecha RS, Jacoby P, Cole CH, Gottardo NG : Morbidity in survivors of child and adolescent meningioma. Cancer $119:$ 4350-4357, 2013

15. Kotecha RS, Junckerstorff RC, Lee S, Cole CH, Gottardo NG : Pediatric meningioma: current approaches and future direction. J Neurooncol $104: 1-10,2011$ 
16. Kotecha RS, Pascoe EM, Rushing EJ, Rorke-Adams LB, Zwerdling T, Gao $X$, et al. : Meningiomas in children and adolescents: a meta-analysis of individual patient data. Lancet Oncol 12 : 1229-1239, 2011

17. Legius $E$, Vles JS, Casaer P, Plets C, Dom R : Intraparenchymal meningioma in a 14-month-old infant: case report. Brain Dev 7 : 622-624, 1985

18. Mamourian AC, Lewandowski AE, Towfighi J : Cystic intraparenchymal meningioma in a child: case report. AJNR Am J Neuroradiol 12 : 366-367, 1991

19. Morimoto M, Aoki H, Sadamitsu N, Nakashima R : Cystic meningioma-report of two cases (author's transl). No Shinkei Geka $4: 805-809$, 1976

20. Nayil K, Makhdoomi R, Malik R, Ramzan A : Intraparenchymal anaplastic meningioma in a child : a rare entity. Asian J Neurosurg 10 : 111-113, 2015

21. Park I, Huh J, Kim JH, Lee SW, Ryu MH, Kang YK : Primary central nervous system marginal zone B-cell lymphoma of the Basal Ganglia mimicking low-grade glioma: a case report and review of the literature. Clin Lymphoma Myeloma 8 : 305-308, 2008

22. Perilongo G, Sutton LN, Goldwein JW, Gusnard D, Schut L, Biegel JA, et al. : Childhood meningiomas. Experience in the modern imaging era. Pediatr Neurosurg 18 : 16-23, 1992

23. Pinto PS, Huisman $T A$, Ahn $E$, Jordan $L C$, Burger $P$, Cohen $K J$, et al. : Magnetic resonance imaging features of meningiomas in children and young adults: a retrospective analysis. J Neuroradiol 39 : 218-226, 2012

24. Rasalkar DD, Chu WC, Cheng FW, Paunipagar BK, Shing MK, Li CK : Atypical location of germinoma in basal ganglia in adolescents: radiological features and treatment outcomes. Br J Radiol 83 : 261-267, 2010

25. Ravindranath K, Vasudevan MC, Pande A, Symss N : Management of pediatric intracranial meningiomas: an analysis of 31 cases and review of literature. Childs Nerv Syst 29 : 573-582, 2013

26. Sakaki S, Nakagawa $K$, Kimura $H$, Ohue $S$ : Intracranial meningiomas in infancy. Surg Neurol 28 : 51-57, 1987

27. Schroeder BA, Samaraweera RN, Starshak RJ, Oechler HW : Intraparenchymal meningioma in a child: CT and MR findings. J Comput Assist Tomogr 11 : 192-193, 1987

28. Schwaighofer BW, Hesselink JR, Press GA, Wolf RL, Healy ME, Berthoty DP : Primary intracranial CNS lymphoma: MR manifestations. AJNR Am J Neuroradiol $10: 725-729,1989$

29. Shimbo $D$, Kato $T$, Takeda $M$, Ikeda $H$ : Intraparenchymal meningioma in a child. Neurol Med Chir (Tokyo) 51 : 793-797, 2011

30. Starshak RJ : Cystic meningiomas in children: a diagnostic challenge. Pediatr Radiol 26 : 711-714, 1996

31. Teo JG, Goh KY, Rosenblum MK, Muszynski CA, Epstein FJ : Intraparenchymal clear cell meningioma of the brainstem in a 2-year-old child. Case report and literature review. Pediatr Neurosurg 28 : 27-30, 1998

32. Wada T, Suzuki M, Beppu T, Arai H, Yoshida Y, Ogawa A, et al. : A case of subcortical meningioma. Acta Neurochir (Wien) $142:$ 209-213, 2000

33. Werbrouck C, Florin D, Van Holsbeeck B, Laridon E, De Weweire $M$, Marrannes J : Intraparenchymal meningioma in a child. JBR-BTR 97 : 46, 2014

34. Zhang J, Chi LY, Meng B, Li F, Zhu SG : Meningioma without dural attachment: case report, classification, and review of the literature. Surg Neurol 67 : 535-539, 2007

35. Zhao SL, Li Y, Tian XY, Li Z, Huang Q, Li B : Intraparenchymal cystic chordoid meningioma: a case report and review of the literature. Neuropathology 31 : 648-653, 2011 